\title{
Dissociation in Conditioned Dopamine Release in the Nucleus Accumbens Core and Shell in Response to Cocaine Cues and during Cocaine-Seeking Behavior in Rats
}

\author{
Rutsuko Ito, Jeffrey W. Dalley, Simon R. Howes, Trevor W. Robbins, and Barry J. Everitt \\ Department of Experimental Psychology, University of Cambridge, Cambridge CB2 3EB, United Kingdom
}

\begin{abstract}
The dopaminergic innervation of the nucleus accumbens is generally agreed to mediate the primary reinforcing and locomotor effects of psychostimulants, but there is less consensus on conditioned dopamine (DA) release during drug-seeking behavior. We investigated the neurochemical correlates of drugseeking behavior under the control of a drug-associated cue [a light conditioned stimulus $(\mathrm{CS}+)]$ and to noncontingent presentations of the CS+ in the core and shell subregions of the nucleus accumbens. Rats self-administered cocaine under a continuous reinforcement schedule in which a response on one of two identical levers led to an intravenous cocaine infusion (0.25 $\mathrm{mg} /$ infusion) and a $20 \mathrm{sec}$ light $\mathrm{CS}+$. Response requirements for cocaine and the CS + were then progressively increased until stable responding was established under a second-order schedule of reinforcement. During microdialysis, rats were presented
\end{abstract}

noncontingently with a set of $10 \mathrm{sec}$ CS+ and neutral tone stimuli (CS-) before and after a 90 min period during which they responded for cocaine under a second-order schedule. Results showed the following: (1) nucleus accumbens DA increased in both the core and shell during intravenous cocaine self-administration; (2) noncontingent presentations of a cocaineassociated CS + led to increased DA release selectively in the nucleus accumbens core; and (3) extracellular DA levels were unaltered in both core and shell during a protracted period of drug-seeking behavior under the control of the same cocaineassociated cue. These results indicate that the mesolimbic dopamine system is activated after exposure to drug-associated stimuli under specific conditions.

Key words: cocaine; dopamine; nucleus accumbens; secondorder schedule; conditioned reinforcement; microdialysis
Exposure to environmental stimuli associated with the effects of stimulant drugs can evoke intense craving and cause relapse in detoxified and abstinent addicts (O'Brien et al., 1990, 1998; Ehrman et al., 1992; Tiffany and Carter, 1998). Such stimuli, through pavlovian conditioning, acquire conditioned reinforcing and incentive motivational properties and are thereby able to generate and maintain drug-seeking behavior (Davis and Smith, 1979; de Wit and Stewart, 1981; Stewart et al., 1984; Phillips and Fibiger, 1990). The mesolimbic dopamine (DA) system innervating the nucleus accumbens (NAcc) is implicated in the primary reinforcing and locomotor effects of psychostimulants (Roberts et al., 1980; Di Chiara and Imperato, 1988; Hurd et al., 1989; Robledo et al., 1992), as well as in potentiating the conditioned reinforcing properties of reward-associated stimuli (Taylor and Robbins, 1984, 1986). In vivo monitoring studies (Fontana et al., 1993; Gratton and Wise, 1994; Kiyatkin and Stein, 1996; Di Ciano et al., 1998) have reported conditioned DA release in the NAcc in response to exposure to environmental or discrete drug-associated stimuli in rats, but there have also been failures to observe such conditioned neurochemical effects, despite evidence of behavioral activation (Barr et al., 1983; Brown and Fibiger, 1992) or concurrent operant drug-seeking behavior (Neisewander et al., 1996; Bradberry et al., 2000). Such apparent discrepancies may have arisen because of differences or limitations in the techniques and protocols used or because of a failure to take into account the anatomical and functional heterogeneity of the NAcc when placing dialysis probes or electrodes.

The elucidation of neurochemical responses associated specifically with craving or drug-seeking has also been limited by selfadministration protocols that fail to distinguish clearly between

\footnotetext{
Received June 1, 2000; revised July 13, 2000; accepted July 20, 2000.

This work was supported by Medical Research Council (MRC) Program Grant G9537855 (to B.J.E. and T.W.R.) and an MRC Cooperative in Brain, Behavior, and Neuropsychiatry.

Correspondence should be addressed to Prof. B. J. Everitt, Department of Experimental Psychology, University of Cambridge, Downing Street, Cambridge CB2 3EB, UK. E-mail: bje10@cus.cam.ac.uk.

Copyright (C) 2000 Society for Neuroscience $\quad 0270-6474 / 00 / 207489-\bullet \$ 15.00 / 0$
}

drug-seeking and drug-taking behavior. Self-administration procedures using low fixed ratio (FR) or progressive ratios of reinforcement cannot clearly dissociate cue-elicited neurochemical responses from drug-induced responses, because the period of responding before any drug infusion is necessarily very brief. In contrast, the use of a second-order schedule of drug reinforcement (Goldberg, 1973; Whitelaw et al., 1996; Arroyo et al., 1998) helps to overcome this problem. Thus, in a typical second-order schedule, a drug-paired light conditioned stimulus $(\mathrm{CS}+)$ is presented contingent on a fixed ratio of lever pressing, and a high rate of such responding can be maintained for prolonged periods of time until the drug itself becomes available, upon completion of a specific number of FR units of responses, after a fixed interval (FI) has elapsed, or both. This allows the investigation of drug-seeking behavior that is both under the control of drug-associated conditioned stimuli and also unconfounded by the reinforcing and response rate-altering effects of the self-administered drug (Goldberg and Tang, 1977; Arroyo et al., 1998).

The NAcc, although a primary site mediating the reinforcing effects of psychomotor stimulants, is also a heterogenous structure with at least two anatomically and functionally distinct subregions: a medial and ventral "shell" region and a more lateral "core" region. (Zahm and Heimer, 1990; Heimer et al., 1991; Jones et al., 1996; David et al., 1998). It has been suggested that the DA innervation of the shell region is especially responsive to primary rewards, such as food (Tanda et al., 1998; Bassareo and Di Chiara, 1999) and drugs of abuse (Di Chiara et al., 1993; Pontieri et al., 1995; Carlezon and Wise, 1996; Tanda et al., 1997). In contrast, the NAcc core region has been implicated in response-reinforcement (instrumental) learning (Kelley et al., 1997) and in subserving behavioral responses to motivationally significant conditioned stimuli (Bassareo and Di Chiara, 1999; Di Chiara, 1998; Parkinson et al., 1999, 2000). Therefore, in the present study, we have used a second-order schedule of cocaine reinforcement (Arroyo et al., 1998) combined with in vivo microdialysis in both the shell and core subregions of the NAcc to investigate the neurochemical correlates of a protracted period of drug-seeking behavior under the control 


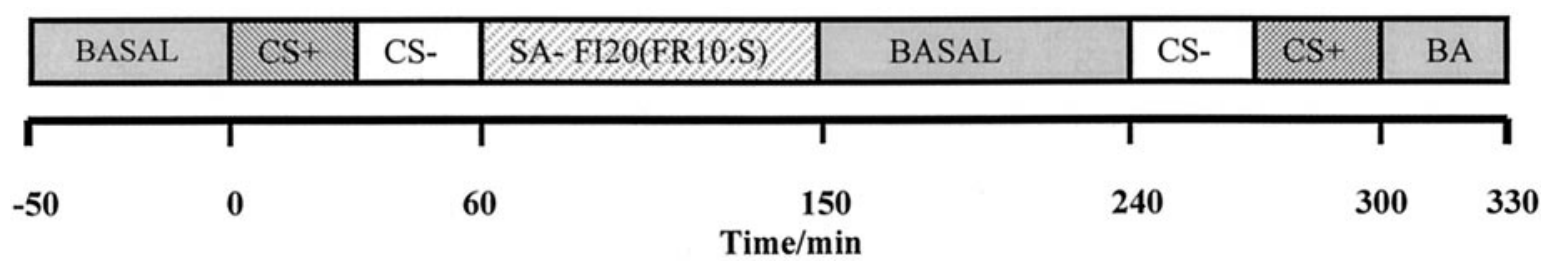

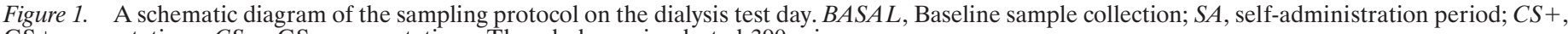
$\mathrm{CS}+$ presentations; $C S-, \mathrm{CS}-$ presentations. The whole session lasted $390 \mathrm{~min}$.

of a cocaine-associated discrete light stimulus, as well as responses to the same drug cue presented noncontingently.

\section{MATERIALS AND METHODS}

Animals. Male Lister hooded rats (Charles River, Kent, UK), weighing between 290 and $360 \mathrm{gm}$ at the beginning of the experiment, were housed in pairs and then individually after surgery, under a reversed $12 \mathrm{hr}$ light/dark cycle (lights off 9:00 A.M.). Water was available ad libitum, and food was made available immediately after a training session, each animal receiving $20 \mathrm{gm}$ Purina lab chow per day, sufficient to maintain preoperative body weight and growth. All experimental sessions were performed during the dark phase, between 9:00 A.M. and 6:00 P.M., and in accordance with the United Kingdom 1986 Animals (Scientific Procedures) Act Project License 90/1324.

Intracerebral cannulation surgery. Animals were anesthetized with Avertin [10 gm of $99 \%$ 2,2,2-tribromoethanol (Sigma-Aldrich, Dorset, UK) in $5 \mathrm{mg}$ of tertiary amyl alcohol and $4.5 \mathrm{ml}$ of PBS (Dulbecco "A"; Unipath Ltd, Basingstoke, UK) in $40 \mathrm{ml}$ of absolute alcohol; $1 \mathrm{ml} / 100 \mathrm{gm}$ body weight, i.p.]. A unilateral guide cannula (BAS Technicol, Congleton, UK) was then lowered and positioned above the nucleus accumbens shell [anteroposterior (AP), $+1.2 \mathrm{~mm}$; lateral $(\mathrm{L}), \pm 0.8 \mathrm{~mm}$; ventral $(\mathrm{V}),-1.75$ $\mathrm{mm}$; incisor bar, $-3.3 \mathrm{~mm}$ ] or core $(\mathrm{AP},+1.2 \mathrm{~mm}$; L, $\pm 1.6 \mathrm{~mm}$; V, -1.75 $\mathrm{mm}$ ) subregion and secured to the skull using dental cement, anchored by four stainless steel screws (BAS Technicol). A removable stainless steel stylet, cut flush with the tip of the cannula, was placed inside the cannula to maintain its patency throughout the training period.

Intravenous catheterization. After stereotaxic surgery, rats were allowed a recovery period for at least $5 \mathrm{~d}$ with food available ad libitum. They were then anesthetized with Avertin and implanted with chronic intravenous jugular catheters as described previously (Caine et al., 1992). The catheter was inserted into the right jugular vein, secured in place by a suture and Superglue, and was passed subcutaneously over the right shoulder to exit dorsally between the scapulae. Antibiotic treatment [flushing daily with 0.1 $\mathrm{ml}$ of Timentin $3.2 \mathrm{~g}$ : $200 \mathrm{mg}$ of potassium clavulanate with $3 \mathrm{gm}$ of ticarcillin (Beecham Research, Welwyn, UK); $66 \mathrm{mg} / 1 \mathrm{ml} 0.9 \%$ sterile saline (Animal Care Ltd., Dunnington, UK)] was given for $5 \mathrm{~d}$ after surgery and was reinstated 3 weeks afterward for $5 \mathrm{~d}$ to minimize postoperative primary and secondary infection. Thereafter, before each selfadministration session, the animals were flushed with $0.1 \mathrm{ml}$ of sterile $0.9 \%$ saline and, at the end of the session, with $0.1 \mathrm{ml}$ of hepranized saline (30 $\mathrm{U} / \mathrm{ml}$ 0.9\% sterile saline; CP Pharmaceuticals Ltd., Wrexham, UK) to maintain catheter patency.

Apparatus. Six operant chambers $(24 \times 20 \times 22 \mathrm{~cm}$; Med Associates, St. Albans, UK) contained within a sound-attenuating box with a ventilating fan were used in the experiment. Each chamber contained a side wall with two 4-cm-wide retractable levers, positioned equidistantly, $10 \mathrm{~cm}$ apart and $5 \mathrm{~cm}$ from the grid floor. Placed $3 \mathrm{~cm}$ above each lever was a round disk ( $\mathrm{cm}$ in diameter) that could be illuminated by a $2.5 \mathrm{~W}, 24 \mathrm{~V}$ light bulb, to serve as a stimulus light. The whole chamber was illuminated by a red 1.8 $\mathrm{W}, 17 \mathrm{~V}$ house light positioned at the top corner of the chamber. The chamber was also equipped with a tone generator (RS Components, Northants, UK) located centrally above the two levers. Intravenous infusions of cocaine were delivered by a software-operated infusion pump (Semat Technical Ltd., St. Albans, UK) placed outside the soundattenuating box, through a counterbalanced single-channel or a dualchannel liquid swivel and an extra length of plastic tubing enclosed in a metal spring, connecting the swivel to the external guide cannula of the catheter mounted on the animal's back or to the external head mount.

Each session could be initiated manually by three rapid presses on one of the two levers, thereby designating the active or drug lever, as opposed to the second, inactive lever on which responding had no programmed consequence. The active and inactive levers were counterbalanced between rats. The beginning of the session was also marked by illumination of the house light. Subsequent depression of the active lever resulted in the retraction of both levers, extinction of the house light and simultaneous illumination of the drug stimulus light for $20 \mathrm{sec}$, and the activation of the infusion pump for $4 \mathrm{sec}$, delivering $0.1 \mathrm{ml}$ of intravenous infusion of cocaine solution $(0.25 \mathrm{mg}$ /infusion). On completion of the $20 \mathrm{sec}$ time-out period, the levers were re-extended, the house light was illuminated, and the stimulus light was extinguished. Additional active lever presses resulted in the same sequence of events leading to cocaine infusions.

The apparatus was controlled by an Acorn Archimedes microcomputer
(Acorn Computers Ltd., Cambridge, UK) running a program written in the BASIC control language Arachnid.

Drugs. Cocaine hydrochloride (McFarlan-Smith, Edinburgh, UK) was dissolved in sterile $0.9 \%$ saline. The dose of cocaine was calculated as the salt.

Self-administration training. Animals were first trained during $2 \mathrm{hr}$ sessions of cocaine self-administration under a continuous reinforcement schedule (fixed ratio 1). Once stable rates of self-administration had been established (10 d), a second-order FRx $\mathrm{FR} y: \mathrm{S})$ schedule of cocaine reinforcement was introduced. Under this schedule, rats were required to make $y$ responses to obtain a single presentation of a $2 \mathrm{sec}$ light $\mathrm{CS}+$, whereas completion of $x$ of these response units resulted in the delivery of cocaine, the illumination of the light CS + for $20 \mathrm{sec}$, the retraction of both levers, and extinction of the house light during a $20 \mathrm{sec}$ time-out period. In the initial stage of training, $x$ was set at 5 and $y$ was 1 . The value for $x$ was then increased to 10 and remained at this value throughout the training. The value for $y$ was progressively increased from 1 to 10 until stable responding was established at FR10(FR10:S). At this stage, a $2 \mathrm{hr}$ delay period before each daily session was gradually introduced over $10 \mathrm{~d}$ for the rats to become accustomed to the baseline collection period during the dialysis experiment. Furthermore, for $3 \mathrm{~d}$ before the test day, rats were pre-exposed to noncontingent presentations of a neutral tone stimulus (CS-) to avoid possible effects of novelty on the neurochemical response. In vivo microdialysis. A $2 \mathrm{~mm}$ microdialysis probe (BAS Technicol) was lowered into the nucleus accumbens via the guide cannula $\sim 18 \mathrm{hr}$ before the start of the experiment. On the test day, the probe was continuously perfused with artificial CSF (aCSF) (in mM: $147 \mathrm{NaCl}, 3 \mathrm{KCl}, 1.3 \mathrm{CaCl}_{2}$, $1 \mathrm{MgCl}_{2}, 0.2 \mathrm{NaH}_{2} \mathrm{PO}_{4}$, and $1.3 \mathrm{Na}_{2} \mathrm{HPO}_{4}$ ) at a rate of $2 \mu \mathrm{l} / \mathrm{min}$. After a 60 min equilibration period, six 10 min baseline samples were collected in plastic vials containing $4 \mu \mathrm{l}$ of aCSF (Fig. 1). For the next three $10 \mathrm{~min}$ samples, the rats received five noncontingent $10 \mathrm{sec}$ light $\mathrm{CS}$ presentations at $1 \mathrm{~min}$ intervals starting at $50 \mathrm{sec}$ into the $10 \mathrm{~min}$ sample. The same pattern of presentation was subsequently repeated with the tone (clicker) for $30 \mathrm{~min}$. A $90 \mathrm{~min}$ self-administration session under a second-order fixed interval schedule FI20 min(FR10:S) was then commenced. No priming injections were ever given. In this newly introduced schedule, animals received a cocaine infusion on the completion of the first FR10 responses made after a fixed interval of $20 \mathrm{~min}$ had elapsed. The animals could thus self-administer a maximum of four cocaine inf usions within $90 \mathrm{~min}$. Using this fixed interval/fixed ratio schedule allowed at least two samples to be obtained during the initial drug-free first interval of drug-seeking behavior. At the end of the session, the levers were retracted, and the house light was extinguished. Nine additional samples were taken for baseline levels to be re-established, and then $\mathrm{CS}+$ and $\mathrm{CS}-$ presentations were given in reverse order and an additional six samples were collected. Sampling continued for another $30 \mathrm{~min}$. On completion of testing, animals were returned to their home cages.

HPLC procedure. DA was determined in dialysate samples by HPLC and electrochemical detection. Separation was achieved by using a Hypersil analytical column $(100 \times 4.6 \mathrm{~mm}$ inner diameter, $3 \mu \mathrm{m})$ and a mobile phase consisting of $8.82 \mathrm{gm} / 1$ trisodium citrate, $2.03 \mathrm{gm} / 1 \mathrm{NaH}_{2} \mathrm{PO}_{4}, 500$ $\mathrm{mg} / 1 \mathrm{Na}-1$-octane sulfonic acid, $22.5 \%$ methanol, $25 \mathrm{mg} / 1 \mathrm{EDTA}$, and 1 $\mathrm{ml} / 1$ triethylamine, $\mathrm{pH} 2.7$ adjusted using orthophosphoric acid. DA was detected by oxidation using a Coulochem II detector (ESA 5014) equipped with a guard cell $(+300 \mathrm{mV})$ and a dual electrode analytical cell (E1, -150 $\mathrm{mV}$; E2, $+150 \mathrm{mV}$ ). Chromatographic data were acquired and processed using Gyncosoft V4.4. The detection limit of DA in aqueous standards was $\sim 2$ fmol on column.

Histological assessment of microdialysis probe placement. Within a week after the completion of the testing, rats were deeply anesthetized with Euthatal (sodium pentobarbitone, $200 \mathrm{mg} / \mathrm{ml}$ ) and perfused with $0.9 \%$ PBS followed by $4 \%$ paraformaldehyde (PFA) in PBS. Brains were then removed, stored in PFA, and transferred to a $20 \%$ sucrose cryoprotectant solution the day before sectioning. Coronal sections $(60 \mu \mathrm{m})$ of the brain were cut and stained with cresyl violet for verification of probe placement.

Data analysis. All analyses were conducted using GBStat (V3.0; Dynamic Microsystems Inc.). Neurochemical data were analyzed using twoway repeated measures ANOVA, with region (two levels: core and shell) as the between subjects factor and time bin as the repeated within-subjects factor (three levels: basal plus CS1, -50 to $60 \mathrm{~min}$; FI, 70-240 min; CS2 plus basal, 250-330 min). In addition, the $20 \mathrm{~min}$ drug-seeking period was analyzed using a two-way ANOVA with region and time as factors. The preceding point $(60 \mathrm{~min})$ was included in this analysis. Fisher's least 


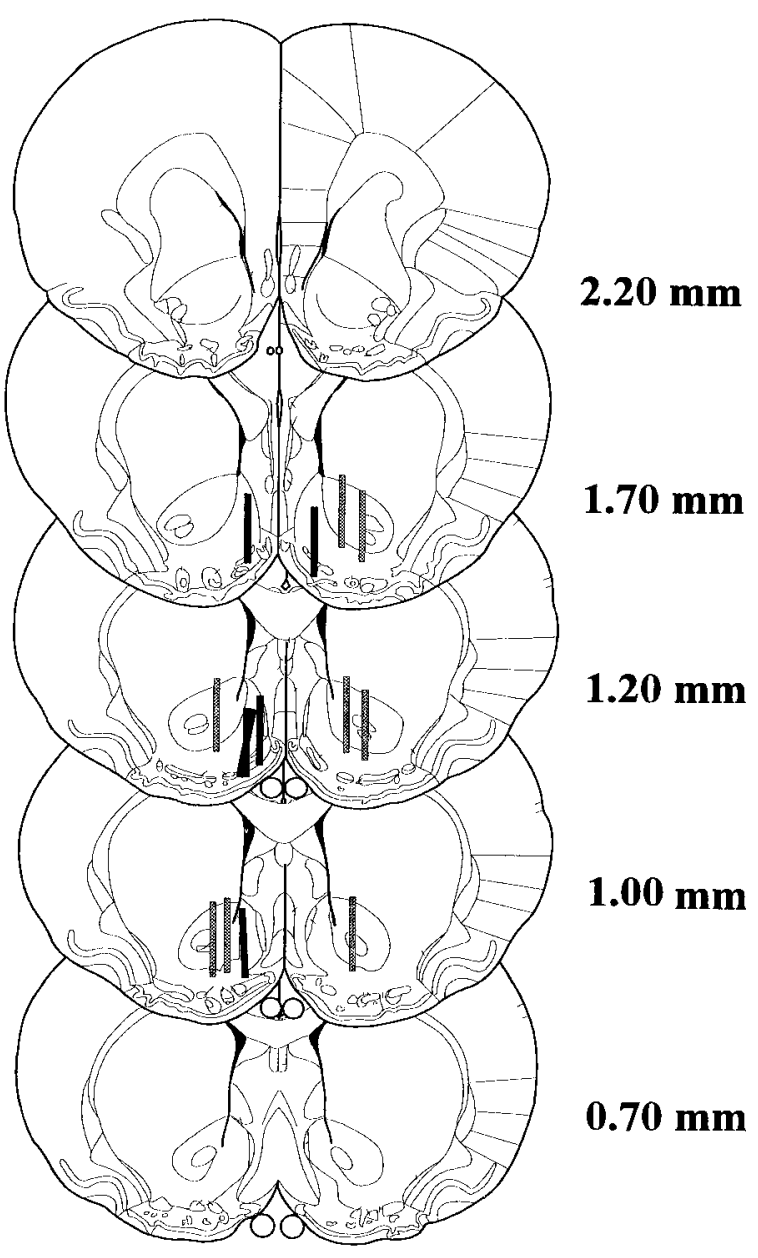

Figure 2. Schematic representation of the locations of the $2 \mathrm{~mm}$ dialysis probe membrane within the nucleus accumbens core (gray; $n=8$ ) and shell (black; $n=6$ ) compartments (distances are in millimeters from the bregma) (adapted from Paxinos and Watson, 1986).

significant difference post hoc test was used for multiple comparisons. Behavioral data were analyzed using two- or three-way repeated measures of ANOVA with region as the between subjects factor and interval and lever as the repeated measures.

\section{RESULTS}

\section{Histological assessment of dialysis probe locations}

Figure 2 shows a schematic representation of the locations of the 2 $\mathrm{mm}$ dialysis probe membrane within the NAcc core $(n=8)$ and shell $(n=6)$ subregions. Data from four animals in which probes were placed outside their intended target were excluded from the study.

\section{Behavioral data}

Figure 3 shows the mean rate of responding on the drug-paired active lever during the four intervals of cocaine self-administration under a FI20(FR10:S) schedule of reinforcement in rats in the NAcc core and shell groups. Every 10th lever press was followed by the presentation of a 2 sec light stimulus ( $\mathrm{CS}+$ ) associated previously with cocaine self-administration during training, and the completion of the first 10 lever responses after an interval of $20 \mathrm{~min}$ resulted in an intravenous cocaine inf usion $(0.25 \mathrm{mg}$ /inf usion) that was also paired with a $20 \mathrm{sec} \mathrm{CS}+$ presentation. All animals received the maximum number (four) of infusions within the 90 min session. As shown in Figure 4, the rate of responding on the active lever showed significant increases with each successive interval in both groups of rats (interval effect, $F_{(3,36)}=14.35, p=$ $0.0001)$. Although overall responding in the shell group was higher than in the core group of animals, ANOVA showed this was not significant $\left(F_{(1,12)}=1.82, p=0.2\right)$. Responding on the inactive lever was significantly lower in both groups of rats as shown in Figure 4 (lever effect, $F_{(1,12)}=169, p=0.0001$ ).

\section{Neurochemical data}

Basal concentrations of $D A$

Basal levels of DA in the NAcc core and shell, taken as the mean \pm SEM fmol/10 min of the first six values obtained before the presentation of the CS + , were $11.81 \pm 0.075$ and $11.85 \pm 0.12$, respectively, and thus were not significantly different between the two regions $\left(F_{(5,60)}=0.39\right)$. Mean changes in the extracellular DA levels in the NAcc core and shell subregions expressed as a percentage of baseline are shown in Figure 5, and absolute values are shown in Figure 6.

\section{Noncontingent $C S+$ and $C S-$ presentations}

As shown in Figures 5 and 6, the first set of noncontingent presentations of the cocaine-associated light $\mathrm{CS}+$ resulted in a significant $150-200 \%$ increase in extracellular DA at time points 10 and 20 min $(p<0.01)$ selectively in the core subregion (time effect, $F_{(11,132)}=2.363, p<0.01$; region $\times$ time interaction, $F_{(11,132)}=$ $2.12, p<0.02)$. In contrast, the presentation of a non-cocaineassociated $\mathrm{CS}-$ did not elevate extracellular DA in either region.

\section{CS + presentation contingent on cocaine-seeking behavior}

At $60 \mathrm{~min}$, levers were extended into the operant chambers signaling the commencement of the self-administration session. The first 20 min of the session allowed the measure of the neurochemical correlates of cocaine-seeking behavior maintained by the CS+ contingent on lever pressing, unaffected by any pharmacological effects of cocaine. As shown in Figures 5 and 6 , there were no significant changes in extracellular DA seen during this period of drug-free cocaine-seeking behavior in either of the NAcc subregions (region, $F_{(1,12)}<0.02$; time, $F_{(2,24)}<0.73$; region $\times$ time, $\left.F_{(2,24)}<0.42\right)$.

\section{$C S+$ presentations contingent on cocaine-seeking behavior after} the self-administration of cocaine

After the first cocaine infusion at $90 \mathrm{~min}$, extracellular DA levels were significantly elevated above baseline levels, and this increase was sustained over subsequent cocaine infusions (maximum of four) in the range of $150-250 \%$ in the core and $200-310 \%$ in the shell $\left(F_{(17,204)}=7.93, p=0.0001\right)$. Fisher's post hoc analyses revealed that this increase from baseline reached significance at time points $130-160 \mathrm{~min}$ in the core $(p<0.01)$ and at time points $90-180 \mathrm{~min}$ in the shell $(p<0.01)$. There was no interaction between region and time with respect to the dopamine response during the self-administration session $(F<1)$. Within 50-60 min after the termination of the self-administration period, extracellular DA declined to levels slightly below the initial baseline (73-85\% in core group; 93-97\% in shell group), but these changes were not statistically different between the two subregions $(F=1.01)$.

In the final phase of the experiment, presentations of the CS+ and CS - were reversed in order. The increase in extracellular DA $(150 \%)$ in the core subregion during the passive presentation of the $\mathrm{CS}+$ (Fig. 5) was again significantly greater than baseline at time points 290 and $300 \mathrm{~min}(p<0.05)$, whereas those in the shell did not change on presentation of the CS+ $(p>1.0)$. As before, presentations of the $\mathrm{CS}-$ were not accompanied by any change in extracellular DA.

\section{DISCUSSION}

Noncontingent presentations of a cocaine-associated cue were associated with significantly increased DA efflux in the core, but not the shell, subregion of the nucleus accumbens. In contrast, presentations of cocaine-associated cues contingent on responding during drug-seeking behavior were not accompanied by any changes in DA efflux. However, after self-administration of cocaine, extracellular DA levels were significantly increased in both the NAcc core and shell subregions. 
Figure 3. Cumulative response record during the period of responding under a second-order FI20 min(FR10:S) schedule, both before and after the self-administration of cocaine The arrow represents the delivery of a cocaine inf usion $(0.75$ $\mathrm{mg}$ /infusion), which was paired with a $20 \mathrm{sec}$ $\mathrm{CS}+$ presentation.
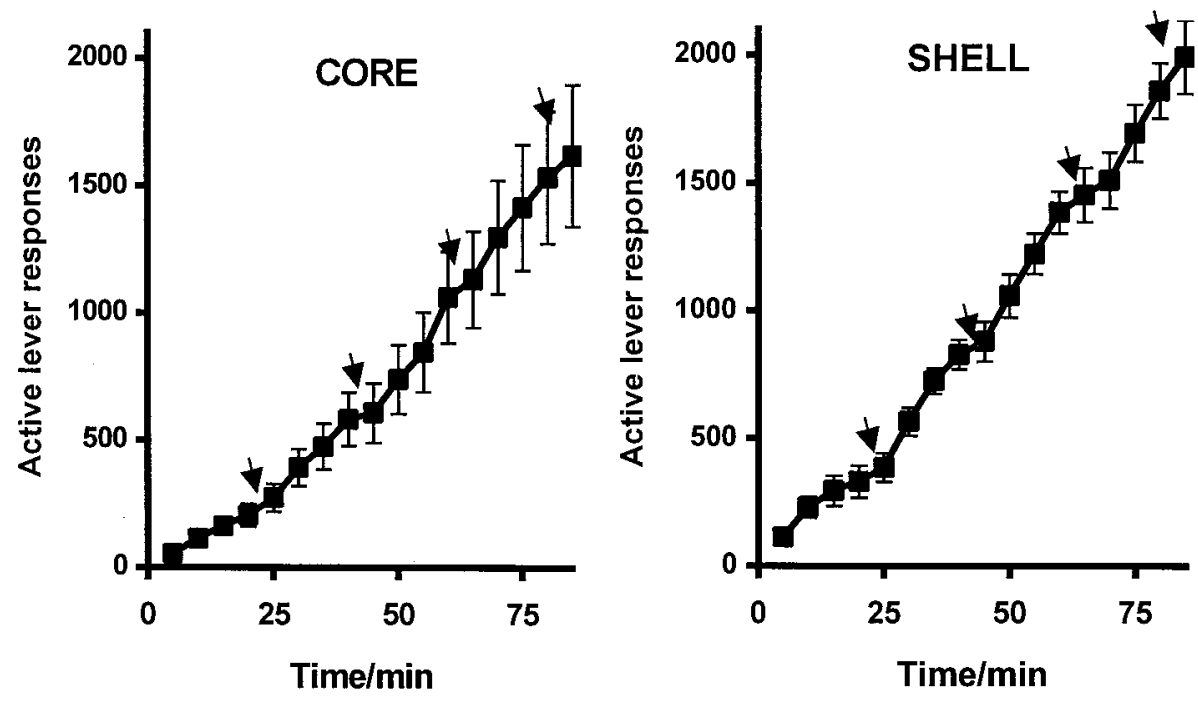
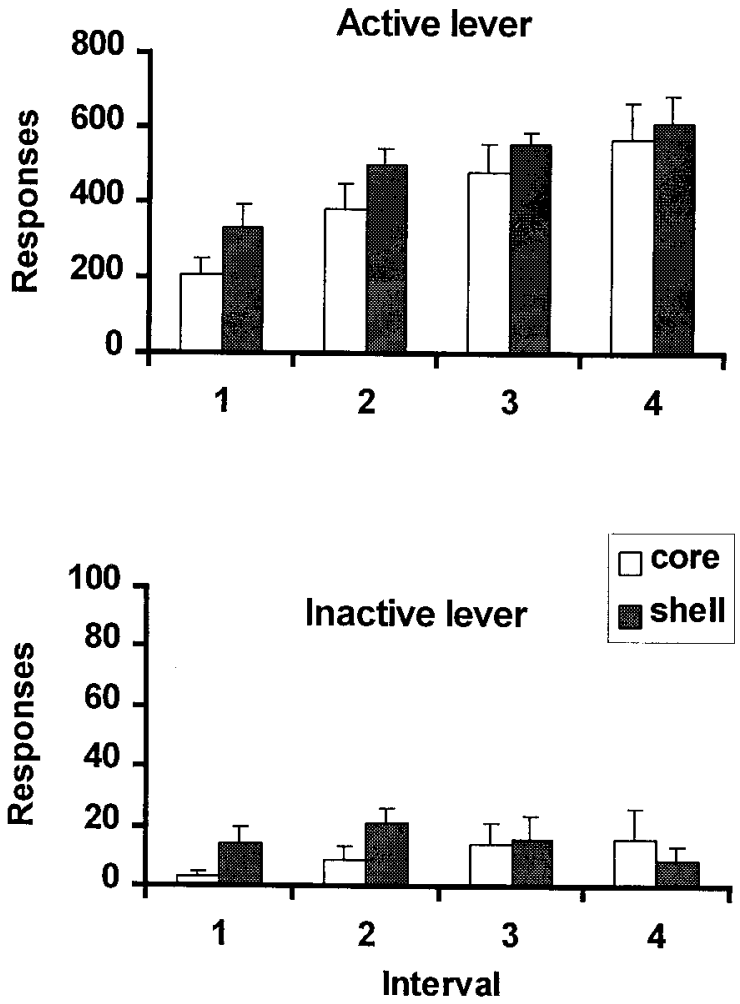

Figure 4. Responses on active and inactive levers before (Interval 1) and after (Intervals 2-4) the self-administration of cocaine. Error bars represent the mean \pm SEM total of active and inactive lever presses made during each of the four intervals in the shell (black; $n=6)$ and core (white; $n=8)$ groups of animals. Every 10th lever press on the active lever resulted in the presentation of a $2 \mathrm{sec}$ light $\mathrm{CS}+$, whereas responding on the inactive lever had no programmed consequence.

\section{Unconditioned effects of cocaine}

The finding of increased extracellular DA in both the core and shell during cocaine self-administration is in contrast to the findings suggesting preferential responsiveness of the DA innervation of the NAcc shell to psychomotor stimulants and other drugs of abuse (Pierce and Kalivas, 1995; Pontieri et al., 1995; Heidbreder and Feldon, 1998; Cadoni and Di Chiara, 1999). One explanation for these different results may lie in the route and method of drug administration. Thus, in the present study cocaine was selfadministered, whereas in the earlier studies the drugs were given noncontingently by the experimenter. However, there are several demonstrations that contingent and noncontingent administration of cocaine differentially affect extracellular DA levels in the nucleus accumbens (Hemby et al., 1997) and amygdala (Wilson et al., 1994), with greater increases occurring after contingent versus noncontingent drug. Cocaine-induced alterations in the activity of NAcc neurons also depend on the passive or active nature of drug administration (Carelli and Deadwyler, 1994). Thus, cocaine selfadministration in the present experiment may have allowed increases in extracellular DA in the core more readily to be measured.

\section{Drug-seeking behavior}

The failure to observe a DA response during active drug-seeking maintained by conditioned stimuli in the present experiment is consistent with the observation of Neisewander et al. (1996) that response-contingent presentations of a CS + associated previously with cocaine self-administration in rats responding in extinction failed to induce an increase in DA overflow in the NAcc (probe placements being predominantly in the core subregion). Moreover, drug-seeking triggered by a visual cue in monkeys was also not associated with changes in extracellular DA in the ventral striatum (Bradberry et al., 2000). These data lead to the speculation that the absence of increases in DA levels in the NAcc concomitant with response-contingent presentations of a $\mathrm{CS}+$ could be attributable to the automated, or habitual, nature of responding under the second-order schedule, the control of which has devolved to a neural system not encompassing the NAcc (Robbins and Everitt, 1999). Not only has drug-seeking behavior been suggested to become compulsive and habitual in the transition from drug abuse to addiction (O'Brien and McLellan, 1996; Robbins and Everitt, 1999), but electrophysiological studies have shown that, after extensive over-training, the response of midbrain DA neurons to conditioned stimuli is gradually attenuated (Ljungberg et al., 1992; Redgrave et al., 1999).

These results are therefore inconsistent with the hypothesis that mesolimbic DA is invariably activated during drug-seeking behavior (de Wit and Stewart, 1981; Robinson and Berridge, 1993). Although it has been shown that DA receptor agonists and antagonists can increase or decrease, respectively, drug-seeking responses (Ettenberg et al., 1996; Shaham and Stewart, 1996; DeVries et al., 1999; Pilla et al., 1999) or reinstate such responses after extinction (Wise et al., 1990; Self et al., 1996; McFarland and Ettenberg, 1997), it remains possible that these effects occur relatively early in the acquisition of drug-seeking or drug-taking behavior or are mediated at sites other than the NAcc, such as the amygdala (Hitchcott and Phillips, 1998; Everitt et al., 1999). Moreover, in these studies of reinstatement of drug-seeking behavior, the subjects' responding has been subjected both to a sometimes long period of extinction and also drug withdrawal. Neither condi- 


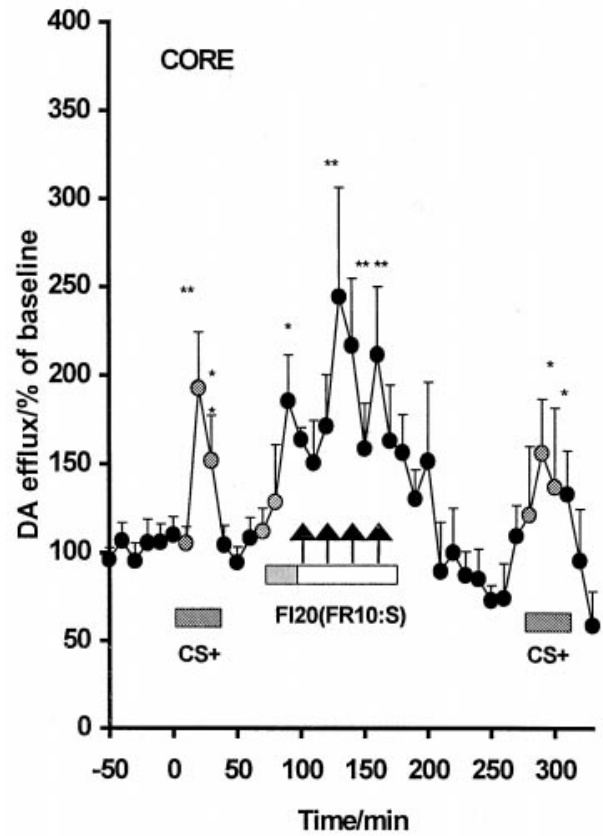

A)

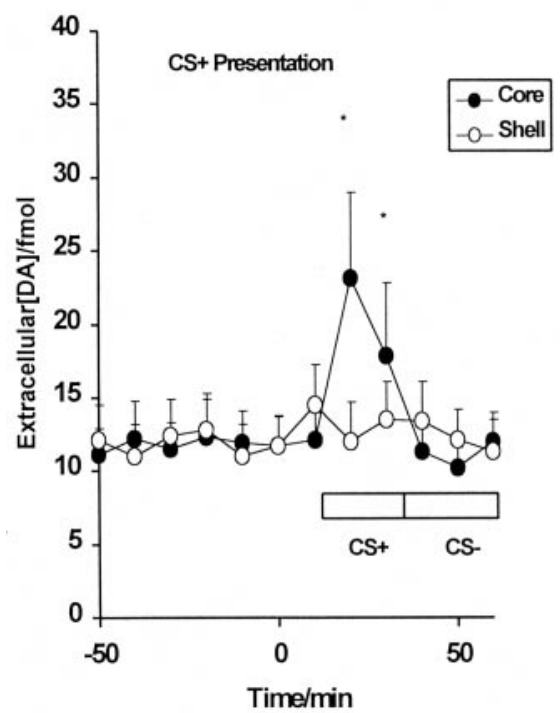

B)

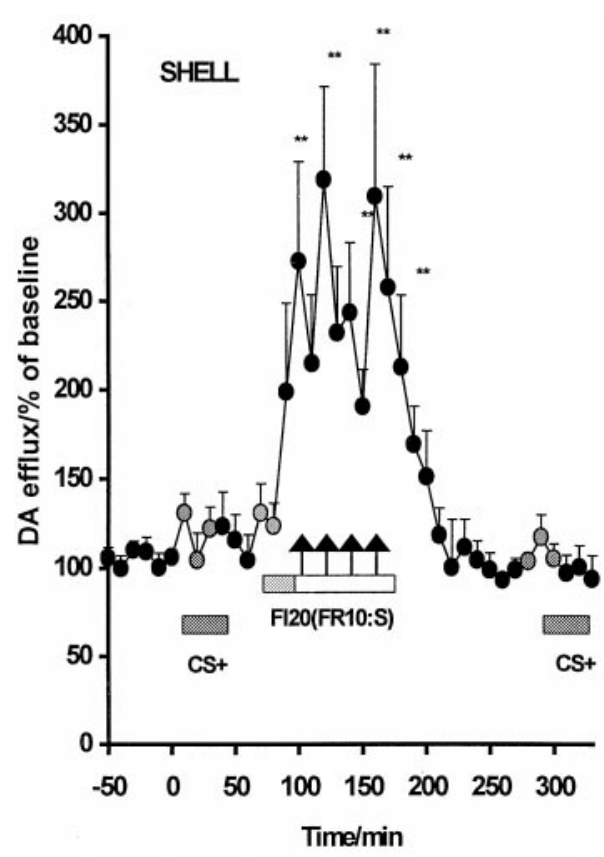

Figure 5. Mean changes in extracellular DA levels in the core and shell subregions in the NAcc (expressed as percentage of baseline \pm SEM). A significant elevation in DA levels $(* p<0.05 ; * * p<0.01)$ compared with baseline levels was observed during the first $\mathrm{CS}+$ presentations selectively in the core subregion. No significant changes in extracellular DA were seen in either region during the first $20 \mathrm{~min}$ of the self-administration session, which provided a measure of drug-seeking behavior unaffected by cocaine itself ( gray shading). The ensuing cocaine inf usions caused significant increases in DA levels in both core and shell subregions (arrows represent time points of cocaine infusions).

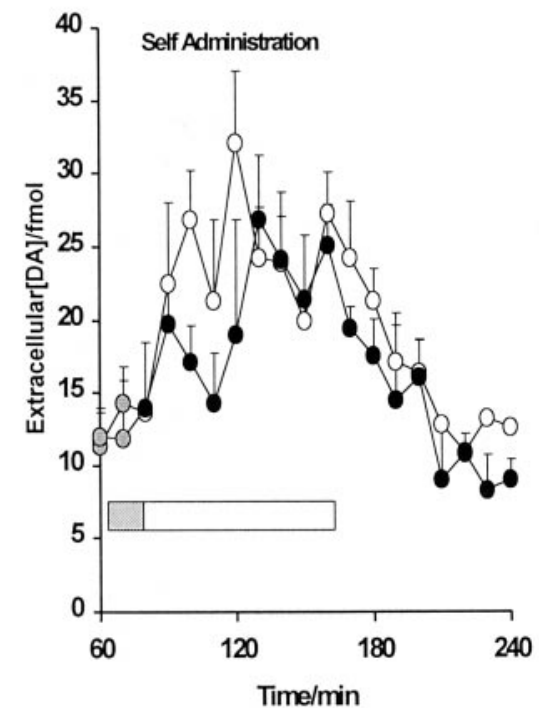

Figure 6. Absolute extracellular DA levels in the core (filled circles) and shell (white circles) subregions during the first set of $\mathrm{CS}+$ presentations and during responding under the second-order schedule both before and after the self-administration of cocaine. The bars indicate the period of CS + and CS - presentations; 10 sec $\mathrm{CS}+/ \mathrm{CS}-$ were presented five times within a 10 min sample. There was a significant increase in DA levels in the core subregion in response to the $\mathrm{CS}+$ presentations $(* p<0.05$; ** $p<0.01)$. The drugseeking period, indicated by gray shading, was not accompanied by a rise in DA levels in either region of the NAcc, whereas during the drug-taking period, significant increases in DA levels were observed in both subregions $(* p<0.05 ; * * p<0.01)$. tion was present in these studies, and it remains possible that dopaminergic mechanisms in cue-dependent drug-seeking might become more prominent after extinction and withdrawal.

The present data also do not support the suggestion that the magnitude of the DA response in the NAcc is correlated with lever pressing rates, as has been reported under high ratio schedules of food reinforcement (Sokolowski et al., 1998; Salamone et al., 1999). Dopamine depletion from the NAcc induced by 6-hydroxydopamine (Robbins et al., 1983; Sokolowski and Salamone, 1998) or infusions of DA receptor antagonists into the NAcc (CorySlechta et al., 1997; Salamone et al., 1999) have been shown to depress instrumental lever pressing, particularly under schedules demanding high response rates. Yet despite the high numbers of responses made by rats under the FI20 min(FR10:S) second-order schedule used in the present study, no increase in extracellular DA in the NAcc was observed until cocaine had been selfadministered. These different results may again reflect the degree of pretraining and the extent to which the instrumental behavior has devolved to habit rather than action-outcome control.

\section{Effect of noncontingent CS+ presentations}

In contrast to the absence of a measurable DA response in the NAcc during drug-seeking behavior, noncontingent presentations of a cocaine-associated CS + evoked a selective increase in extracellular DA in the core, but not the shell, of the NAcc. This result extends the observation of Di Ciano et al. (1998) who found conditioned increases in DA oxidation currents in the NAcc in response to passive presentation of a flashing light stimulus that had been paired previously with either self-administered or noncontingent amphetamine administration. Similarly, presentations of a drug-associated CS + alone before a self-administration session were also accompanied by an increased DA signal in the NAcc (Gratton and Wise, 1994; Kiyatkin and Stein, 1995, 1996).

The selective DA response to noncontingent presentations of the 
$\mathrm{CS}+$ in the core subregion supports the observation of Bassareo and Di Chiara (1999), who also reported that a CS + associated with a highly palatable and calorific food elicited strong appetitive behavioral responses and a concomitant rise in DA levels selectively in the core subregion of the NAcc. Moreover, the increased DA efflux in the NAcc core that followed "unexpected" presentations of the CS + in the present study is consistent with electrophysiological data showing that midbrain DA neurons increased their activity specifically to the unexpected presentation of rewards or conditioned stimuli, whereas such responses were not evident for expected positively reinforcing stimuli, whether conditioned or not (Romo and Schultz, 1990; Schultz et al., 1994; Schultz, 1998).

\section{Pavlovian conditioning, conditioned reinforcement, and drug-seeking behavior}

The results of these experiments indicate important and subtle differences in the ways in which drug-associated stimuli influence drug-seeking behavior and the extent to which this involves activation of the mesolimbic DA system. Thus, although the pavlovian $\mathrm{CS}+$ eliciting property of a cocaine-conditioned reinforcer is sufficient to increase DA selectively in the NAcc core, this effect is apparently unnecessary for the maintenance of drug-seeking behavior by the contingent presentation of the stimulus as a conditioned reninforcer. Therefore, this aspect of the maintenance of drug-seeking is independent of the mesolimbic DA system, whereas the primary reinforcing action of cocaine clearly is not. The observation that conditioned reinforcement (i.e., response-produced $\mathrm{CS}+$ presentations) did not increase DA levels in the NAcc during drug-seeking is also consistent with our earlier results that DA depletion from the NAcc (Taylor and Robbins, 1986) or DA receptor blockade in the NAcc (Wolterink et al., 1993) does not decrease the effects of conditioned reinforcers per se but only their amplification by stimulant drugs.

The particular circumstances under which a drug-associated $\mathrm{CS}+$ does affect drug-seeking behavior via activation of the mesolimbic DA system therefore remain uncertain. One circumstance may be the elicitation of drug-seeking or drug-taking behavior because, after extinction, such cues are known to reinstate drug self-administration (de Wit and Stewart, 1981; Stewart et al., 1984) and drug-seeking under a second-order schedule of reinforcement (Arroyo et al., 1998). Moreover, Weiss et al. (2000) have shown that DA is increased in the NAcc and amygdala by exposure to a cocaine cue that also reinstated responding after a prolonged period of extinction of cocaine self-administration. Another possibility, yet to be studied directly, is that unexpected presentation of drug-cues may facilitate, that is increase the rate of, drug-seeking behavior, much as has been demonstrated for the facilitative effect of a pavlovian $\mathrm{CS}+$ on responding for an ingestive reward (Lovibond, 1983). Indeed, this influence of a CS+ on a seeking response for food is abolished by lesions of the NAcc core, but not shell (Hall et al., 1999), and by the DA receptor antagonist pimozide (Dickinson et al., 2000), whereas intra-accumbens infusions of D-amphetamine potentiate the response-incremental effects of a pavlovian CS + (Wyvell and Berridge, 2000), much as they potentiate conditioned reinforcers (Taylor and Robbins, 1984).

In summary, this study has helped to resolve apparent discrepancies in the literature in which conditioned stimuli have been reported to increase, or to have no effect on, DA overflow in the NAcc. The present investigation has shown both effects: a lack of impact when the $\mathrm{CS}+$ is acting to maintain drug-seeking behavior under a second-order schedule (analogous to habitual responding postulated in human drug abusers) (O'Brien and McLellan, 1996; Tiffany and Carter, 1998); and a significant increase when the same $\mathrm{CS}+$ is presented noncontingently for the first occasion after a history of contingent presentation, possibly consistent with the postulated role of such stimuli in eliciting drug craving and reinstatement behaviors.

\section{REFERENCES}

Arroyo M, Markou A, Robbins TW, Everitt BJ (1998) Acquisition, maintenance and reinstatement of intravenous cocaine self-administration under a second-order schedule of reinforcement in rats: effects of conditioned cues and unlimited access to cocaine. Psychopharmacology 140:331-344.

Barr GA, Sharpless NS, Cooper S, Schiff SR (1983) Classical conditioning, decay and extinction of cocaine-induced hyperactivity and stereotypy. Life Sci 33:1341-1351.

Bassareo V, Di Chiara G (1999) Differential responsiveness of dopamine transmission to food-stimuli in nucleus accumbens shell/core compartments. Neuroscience 89:637-641.

Bradberry CW, Barrett-Larimore RL, Jatlow P, Rubino SR (2000) Impact of self-administered cocaine and cocaine cues on extracellular dopamine in mesolimbic and sensorimotor striatum in rhesus monkeys. J Neurosci 20:3874-3883

Brown EE, Fibiger HC (1992) Cocaine-induced conditioned locomotion: absence of associated increases in dopamine release. Neuroscience 48:621-629.

Cadoni C, Di Chiara G (1999) Reciprocal changes in dopamine responsiveness in the nucleus accumbens shell and core and in the dorsal caudate-putamen in rats sensitized to morphine. Neuroscience 90:447-455.

Caine SB, Lintz R, Koob GF (1992) Intravenous drug self-administration techniques in animals. In: Behavioural neuroscience: a practical approach (Sahgal A, ed), pp 117-143. Oxford: Oxford UP.

Carelli RM, Deadwyler SA (1994) A comparison of nucleus accumbens neuronal firing patterns during cocaine self-administration and water reinforcement in rats. J Neurosci 14:7736-7746.

Carlezon WA, Wise RA (1996) Rewarding actions of phencyclidine and related drugs in nucleus accumbens shell and frontal cortex. J Neurosci 16:3112-3122

Cory-Slechta DA, Pazmino R, Bare C (1997) The critical role of nucleus accumbens dopamine systems in the mediation of fixed interval schedulecontrolled operant behaviour. Brain Res 764:253-256.

David JD, Zahnister NR, Hoffer BJ, Gerhardt GA (1998) In vivo electrochemical studies of dopamine clearance in subregions of rat nucleus accumbens: differential properties of the core and shell. Exp Neurol 153:277-286.

Davis WM, Smith SG (1979) Role of conditioned reinforcers in the initiation, maintenance and extinction of drug-seeking behaviour. Pavlov J Biol Sci 11:222-236.

De Vries TJ, Schoffelmeer ANM, Binnekade R, Vanderschuren LJMJ (1999) Dopaminergic mechanisms mediating the incentive to seek cocaine and heroin following long-term withdrawal of IV drug selfadministration. Psychopharmacology 143:254-260.

de Wit H, Stewart J (1981) Reinstatement of cocaine-reinforced responding in the rat. Psychopharmacology 75:134-143.

Di Chiara G (1999) Drug addiction as dopamine-dependent associative learning disorder. Eur J Pharmacol 375:13-30.

Di Chiara G, Imperato A (1988) Drugs abused by humans preferentially increase synaptic dopamine concentrations in the mesolimbic system of freely moving rats. Proc Natl Acad Sci USA 85:5274-5278.

Di Chiara G, Tanda G, Frau R, Carboni E (1993) On the preferential release of dopamine in the nucleus accumbens by amphetamine: further evidence obtained by vertically implanted concentric dialysis probes. Psychopharmacology Berl 112:398-402.

Di Ciano P, Blaha CD, Phillips AG (1998) Conditioned changes in dopamine oxidation currents in the nucleus accumbens of rats by stimuli paired with self-administration or yoked-administration of $d$-amphetamine Eur J Neurosci 10:1121-1127.

Dickinson A, Smith J, Mirenowicz J (2000) Dissociation of Pavlovian and instrumental learning under dopamine antagonism. Behav Neurosci 114:468-483.

Ehrman RN, Robbins SJ, Childress AR, O’Brien CP (1992) Conditioned responses to cocaine-related stimuli in cocaine abuse patients. Psychopharmacology 107:523-529.

Ettenberg A, MacConnell LA, Geist TD (1996) Effects of haloperidol in a response-reinstatement model of heroin relapse. Psychopharmacology 124:205-210.

Everitt BJ, Parkinson JA, Olmstead MC, Arroyo M, Robledo P, Robbins TW (1999) Associative processes in addiction and reward: the role of amygdala-ventral striatal systems. Ann NY Acad Sci 877:412-438.

Fontana DJ, Post RM, Pert A (1993) Conditioned increases in mesolimbic dopamine overflow by stimuli associated with cocaine. Brain Res 629:31-39.

Goldberg SR (1973) Comparable behavior maintained under fixed-ratio and second-order schedules of food presentation, cocaine injection or D-amphetamine injection in the squirrel monkey. J Pharmacol Exp Ther 186:18-30.

Goldberg SR, Tang AH (1977) Behavior maintained under second-order schedules of intravenous morphine injection in squirrel and rhesus monkeys. Psychopharmacology 51:235-242.

Gratton A, Wise RA (1994) Drug- and behavior-associated changes in dopamine-related electrochemical signals during intravenous cocaine self-administration. J Neurosci 14:4130-4146.

Hall J, Parkinson JA, Connor TMF, Di Ciano P, Dickinson A, Everitt BJ (1999) The role of amygdala-ventral striatal sub-systems in Pavlovian to instrumental transfer. Soc Neurosci Abstr 41:2.

Heidbreder C, Feldon J (1998) Amphetamine-induced neurochemical and 
locomotor responses are expressed differentially across the anteroposterior axis of the core and shell subterritories of the nucleus accumbens. Synapse 29:310-322.

Heimer L, Zahm DS, Churchill L, Kalivas PW, Wohltmann C (1991) Specificity in the projection patterns of accumbal core and shell in the rat. Neuroscience 41:89-125.

Hemby SE, Co C, Koves TR, Smith JE, Dworkin TR (1997) Differences in extracellular dopamine concentrations in the nucleus accumbens during response-dependent and response-independent cocaine administration in the rat. Psychopharmacology 133:7-16.

Hitchcott PK, Phillips GD (1998) Double dissociation of the behavioural effects of $\mathrm{R}(+)$ 7-OH-DPAT infusions in the central and basolateral amygdala nuclei upon Pavlovian and instrumental conditioned appetitive behaviours. Psychopharmacology 140:458-469.

Hurd Y, Weiss F, Koob GF, Ungerstedt U (1989) Cocaine reinforcement and extracellular DA overflow in rat nucleus accumbens: an in vivo microdialysis study. Brain Res 498:199-204.

Jones SR, O'Dell SJ, Marshall JF, Wightman RM (1996) Functional and anatomical evidence for different dopamine dynamics in the core and shell of the nucleus accumbens in slices of rat brain. Synapse 23:224-231.

Kelley AE, Smith-Roe SL, Holahan MR (1997) Response-reinforcement learning is dependent on $N$-methyl-D-aspartate receptor activation in the nucleus accumbens core. Proc Natl Acad Sci USA 94:12174-12179.

Kiyatkin EA, Stein EA (1995) Fluctuations in nucleus accumbens dopamine during cocaine self-administration behaviour: an in vivo electrochemical study. Neuroscience 54:599-617.

Kiyatkin EA, Stein EA (1996) Conditioned changes in nucleus accumbens dopamine signal established by intravenous cocaine in rats. Neurosci Lett 211:73-76

Ljungberg T, Apicella P, Schultz W (1992) Responses of monkey midbrain dopamine neurons during learning of behavioural reactions. J Neurophysiol 67:145-163.

Lovibond PF (1983) Facilitation of instrumental behaviour by a Pavlovian appetitive conditioned stimuli. J Exp Psychol Anim Behav Process 9:225-247.

McFarland K, Ettenberg A (1997) Reinstatement of drug-seeking behavior produced by heroin-predictive environmental stimuli. Psychopharmacology 131:86-92.

Neisewander JL, O’Dell LE, Tran-Nguyen LTL, Castaneda E, Fuchs RA (1996) Dopamine overflow in the nucleus accumbens during extinction and reinstatement of cocaine self-administration behavior. Neuropsychopharmacology 15:506-514.

O'Brien CP, McLellan AT (1996) Myths about the treatment of addiction. Lancet 347:237-240.

O'Brien CP, Childress AR, McLellan T, Ehrman R (1990) Integrating systemic cue exposure with standard treatment in recovering drug dependent patients. Addict Behav 15:355-365

O'Brien CP, Childress AR, Ehrman R, Robbins SJ (1998) Conditioning factors in drug abuse: can they explain compulsion? J Psychopharmacol 12:15-22.

Parkinson JA, Olmstead MC, Burns LH, Robbins TW, Everitt BJ (1999) Dissociation in effects of lesions of nucleus accumbens core and shell in appetitive Pavlovian approach behavior and the potentiation of conditioned reinforcement and locomotor activity by D-amphetamine. J Neurosci 19:2401-2411.

Parkinson JA, Willoughby PJ, Robbins TW, Everitt BJ (2000) Disconnection of the anterior cingulate cortex and nucleus accumbens core impairs Pavlovian approach behavior: further evidence for limbic cortical-ventral striatopallidal systems. Behav Neurosci 114:42-63.

Paxinos G, Watson C (1986) The rat brain in stereotaxic coordinates, Ed 2. Sydney: Academic.

Phillips AG, Fibiger HC (1990) Role of reward and enhancement if conditioned reward in persistence of responding for cocaine. Behav Pharmacol 1:269-282.

Pierce RC, Kalivas PW (1995) Amphetamine produces sensitized increases in locomotion and extracellular dopamine preferentially in the nucleus accumbens shell of rats administered repeated cocaine. Brain Res 567:169-174.

Pilla M, Perachon S, Sautel F, Garrido F, Mann A, Wermuth CG, Schwartz JC, Everitt BJ, Sokoloff P (1999) Selective inhibition of cocaine-seeking behaviour by a partial dopamine D3 receptor agonist. Nature 400:371-375.

Pontieri FE, Tanda G, Di Chiara G (1995) Intravenous cocaine, morphine, and amphetamine preferentially increase extracellular dopamine in the "shell" as compared with the "core" of the rat nucleus accumbens. Proc Natl Acad Sci USA 92:12304-12308.

Redgrave P, Prescott TJ, Gurney K (1999) Is the short-latency dopamine response too short to signal reward error? Trends Neurosci 22:146-151.

Robbins TW, Everitt BJ (1999) Drug addiction: bad habits add up. Nature 398:567-570.
Robbins TW, Roberts DCS, Koob GF (1983) Effects of $d$-amphetamine and apomorphine upon operant behavior and schedule-induced licking in rats with 6-hydroxydopamine-induced lesions of the nucleus accumbens J Pharmacol Exp Ther 224:662-673.

Roberts DCS, Koob GF, Klonoff HC, Fibiger HC (1980) Extinction and recovery of cocaine self-administration following 6-hydroxydopamine lesions of the nucleus accumbens. Pharmacol Biochem Behav 12:781-787.

Robinson TE, Berridge KC (1993) The neural basis of drug craving: an incentive-sensitization theory of addiction. Brain Res Rev 18:247-291.

Robledo P, Maldonado-Lopez R, Koob GF (1992) Role of dopamine receptors in the nucleus accumbens in the rewarding properties of cocaine. Ann NY Acad Sci 654:509-512.

Romo R, Schultz W (1990) Dopamine neurons of the monkey midbrain and contingencies of responses to active touch during self-initiated arm movements. J Neurophysiol 63:592-606.

Salamone JD, Aberman JE, Sokolowski JD, Cousins MS (1999) Nucleus accumbens dopamine and rate of responding: neurochemical and behavioral studies. Psychobiology 27:236-247.

Schultz W (1998) Predictive reward signal of dopamine neurons. J Neurophysiol 80:1-27.

Schultz W, Romo R, Ljunberg T, Mirenovicz J, Hollerman JR, Dickinson A (1994) Reward and related signals carried by DA neurons. In: Models of information processing in the basal ganglia (Houk et al., ed). Cambridge, MA: MIT.

Self DW, Barnhart WJ, Lehman DA, Nestler EJ (1996) Opposite modulation of cocaine-seeking behavior by D1-like and D2-like dopaminereceptor agonists. Science 271:1586-1589.

Shaham Y, Stewart J (1996) Effects of opioid and dopamine receptor antagonists on relapse induced by stress and re-exposure to heroin in rats. Psychopharmacology 125:385-391.

Sokolowski JD, Salamone JD (1998) The role of accumbens dopamine in lever pressing and response allocation: effects of 6-OHDA injected into core and dorsomedial shell. Pharmacol Biochem Behav 59:557-566.

Sokolowski JD, Conlan AN, Salamone JD (1998) A microdialysis study of nucleus accumbens core and shell dopamine during operant responding in the rat. Neuroscience 86:1001-1009.

Stewart J, de Wit H, Eikelboom R (1984) Role of unconditioned and conditioned drug affects in the self-administration of opiates and stimulants. Psychol Rev 91:251-268.

Tanda GL, Di Chiara G (1998) A dopamine-mu(1) opioid link in the rat ventral tegmentum shared by palatable food (Fonzies) and nonpsychostimulant drugs of abuse. Eur J Neurosci 10:1179-1187.

Tanda G, Pontieri FE, Di Chiara G (1997) Cannabinoid and heroin activation of mesolimbic dopamine transmission by a common mu 1 opioid receptor mechanism. Science 276:2048-2050.

Taylor JR, Robbins TW (1984) Enhanced behavioural control by conditioned reinforcers following microinjections of $d$-amphetamine into the nucleus accumbens. Psychopharmacology 84:405-412.

Taylor JR, Robbins TW (1986) 6-Hydroxydopamine lesions of the nucleus accumbens, but not the caudate-nucleus, attenuate enhanced responding with reward-related stimuli produced by intra-accumbens D-amphetamine. Psychopharmacology 90:390-397.

Tiffany TT, Carter BL (1998) Is craving the source of compulsive drug use? J Psychopharmacol 12:23-30.

Weiss F, MaldonadoVlaar CS, Parsons LH, Kerr TM, Smith DL, BenShahar O (2000) Control of cocaine-seeking behavior by drug-associated stimuli in rats: effects on recovery of extinguished operant-responding and extracellular dopamine levels in amygdala and nucleus accumbens. Proc Natl Acad Sci USA 97:4321-4326.

Whitelaw RB, Markou A, Robbins TW, Everitt BJ (1996) Excitotoxic lesions of the basolateral amygdala impair the acquisition of cocaineseeking behaviour under a second-order schedule of reinforcement. Psychopharmacology 127:213-224.

Wilson JM, Nobrega JN, Corrigal WA, Coen KM, Shannak K, Kish SJ (1994) Amygdala dopamine levels are markedly elevated after selfadministration but not passive-administration of cocaine. Brain Res 668:39-45.

Wise RA, Murray A, Bozarth MA (1990) Bromocriptine selfadministration and bromocriptine-reinstatement of cocaine-trained and heroin-trained lever pressing in rats. Psychopharmacology 100:355-360.

Wolterink G, Phillips GD, Cador M, Donselaar-Wolterink I, Robbins TW, Everitt BJ (1993) Relative roles of ventral striatal D1 and D2 dopamine receptors in responding with conditioned reinforcement. Psychopharmacology 110:355-364.

Wyvell CL, Berridge KC (2000) Intra-accumbens amphetamine increases the pure incentive salience of a Pavlovian cue for food reward: enhancement of "wanting" without either "liking" or reinforcement. J Neurosci, in press.

Zahm DS, Heimer L (1990) Two transpallidal pathways originating in the rat nucleus accumbens. J Comp Neurol 302:437-446. 